Policy Research

WORKING PAPER 1223

How Robust Is

a Poverty Profile?

Martin Ravallion

Benu Bidani
The World Bank

Policy Research Deparment

Poverty and Human Resources Division

November 1993

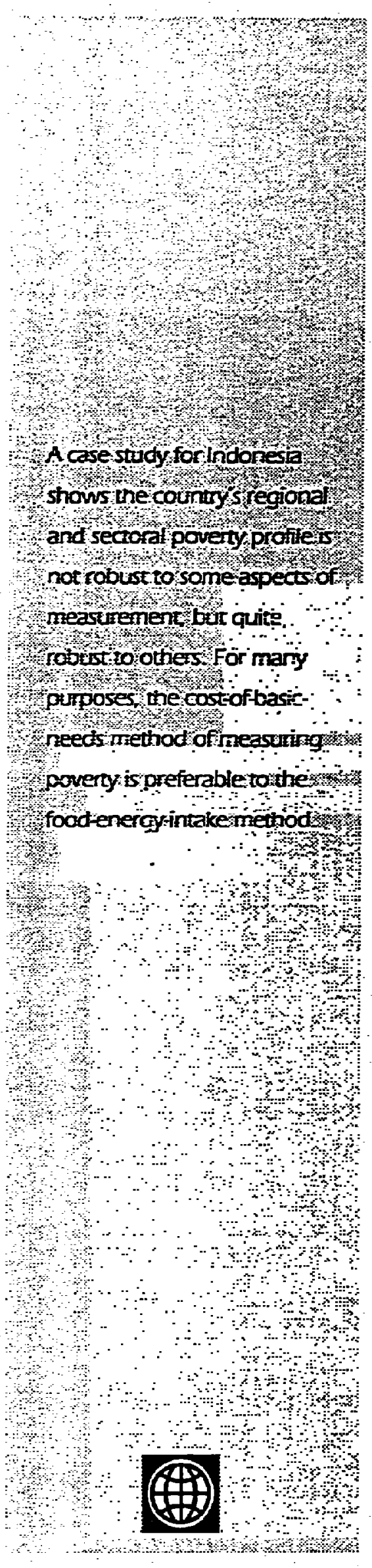




\section{Summary findings}

Comparisons of poverty - indicating where or when poverty is greatest, for example - typically matter far more to policy choices than aggregate poverty measures, such as how many people are deemed "poor." So Ravallion and Bidani examine how measurement practices affect empirical poverty profiles. They discuss the pros and cons of alternative approaches to developing a poverty profile and use those approaches on the same data ser.

In Indonesia, as in many countries, past methods of building poverty profiles have used the food-energyincake method, defining the poverty line as the nominal consumprion spending at which a person typically attains a predetermined food energy incake in each subgroup. Ravallion and Bidani argue that this method can yield differences in poverty lines (berween urban and rural areas, for example) thar exceed the cost-of-living differences the poor face. So, that method can mislead policy choices aimed at reducing absolute poverty.

For comparison, they explore a cost-of-basic-needs method, whereby an explicir bundle of foods typically consumed by the poor is valued at local prices, with a minimal allowance for nonfood goods consistent with spending by the poor. This approach, though not ideal, is a conceptually transparent operational alternative that can be implemented with available data. They argue that this approach is more likely to generare a consistent poverty profile in that two people with the same measured standard of living - purchasing power for basic consumption needs - will be treated the same way. This refinement of past approaches retains some seemingly desirable fearures (such as concern for the tastes of the poor) and avoids others (such as the implicit use of a higher real poverty line in richer regions of the same country).

For Indonesia, the cost-of-basic-needs method finds more incidence, depth, and severity of poverry in rural areas, wherens the food-energy-incake merhod finds ail measures of poverty worse in urban areas. The ranking of regions (provinces divided into rural and urban) by the two methods has virually zero correlarion. The poverty profile by principal sector of employment is less sensirive to the choice of method, particularly in urban areas.

This case study supports the conclusion that policymakers should be wary of underiying differences between methods of estimating poverty measures.

The cost-of-basic-needs approach is fairly robust to several other methodological choices, nocably changes in the composition of the basic needs bundle (which determines the overall level of the poverny line), differences in the functional form of the poverty measure, and adjustment for spatial differences in prices, issues that have dominated debates on how to measure poverty- Ironically, the results of this study suggest that these issues marter less to poverty rankings (and hence to policy conclusions) than do the choices made in mapping a given specification of basic needs into monetary poverty lines.

This paper - a product of the Poverty and Human Resources Division, Policy Research Department - is part of a larger effort in the department to evaluare alrernarive methodologies for poverty analysis and advise on best practice. Copies of the paper are available free from the World Bank, $1818 \mathrm{H}$ Streer NW, Washington, DC 20433. Please contactPatricia Cook, room N5-05T, extension 33902 (33 pages). November 1993.

The Policy Research Working Paper Series disseminates the findings of work in progress to encourage the excharge of ideas about development issues An objective of the series is to get the findings out quickly, even if the presentations are less than fully polisbed. The papers carry the names of the auchors and should be used and cited accondingly. The fondings, interpretations, and conclusions are the authors oum and should not be attributed to the World Bank its Execuivite Board of Directors, or any of its memiber countries. 


\title{
How Robust is a Poverty Profile?
}

\author{
Martin Ravallion and Benu Bidani*
}

- Poverty and Human Resources Division, Policy Research Department, World Bank. We have had helpful comments or assistance from Anne Booth, Shubham Chaudhuri, Shaohua Chen, Gaurav Datt, Paul Glewwe, Peter Lanjouw, Nicholas Prescott, Dominique van de Walle. seminar participants at the Central Bureau of Statistics, Indonesia, and Department of Economics, Vanderbilt University, and the Review's editor, editorial board, and referees. We are also grateful to the staff of Indonesia's Central Bureau of Statistics for providing the data used here, and for the useful discussions we have had with them during the course of this study. 


\section{Introduction}

When practices in empirical work have bearing on policy choices they deserve especially close scrutiny. Constructing a povertv profrile - showing how the extent of poverty varies across subgroups of a population - is typically the first step in formulating an anti-poverty policy. Do the assumptions made matter to the policies advocated?

This paper critically examines popular methods of constructing a poverty profile. We discuss the strengths and weaknesses of the two most common methods of setting poverty lines. While neither is perfect, we argue that one of these methods is preferable when the poverty profile is intended to inform policies aimed at reducing absolute poverty.

Regional and employment profiles of poverty in Indonesia for 1990 are constructed by alternative methods, so as to test the robustness of the poverty profile to the assumptions made. The following section discussos the alternative approaches in the abstract. Section 3 then describes the one we have adopred as the "benchmark" for comparison purposes. The empirical results for Indonesia are discussed in section 4. Our conclusions are summarized in section 5.

\section{Approaches to Constructing a Poverty Profile}

A "poverty profile" shows how a measure of poverty varies across subgroups of a population such as region of residence or sector of employment. Typically, people in each sub-group are classified as "poor" if their consumption expenditure is below a subgroup specific "poverty line". Poverty lines can thus be interpreted as deflators which establish the welfare comparability of nominal expenditures (or incomes) across the poverty profile.

How should one set poverty lines? When the aim is to inform policy, one appealing criterion is that whether or not a given standard of living constitutes poverty should not depend on which subgroup the person with that standard of living belongs. We call a poverty profile "consistent" if it respects this principle. For example, suppose we are comparing two households deemed to have 
exactly the same standard of living - in all relevant respects - but one works mainly on a farm while the other works in a factory; the poverty profile would be inconsistent if it classified one of these as poor and the other as not. Similarly, whether or not a given standard of living constitutes poverty should not depend on where the person with that standard of living happens to live. Consistency requires that the poverty line is fixed in terms of the level of living it implies. (It also has implications for the properties of the functional form of a poverty measure; though that is not our concern here; see Foster and Shorrocks, 1991.) To test consistency we must specify a measure of the "standard of living"; a poverty profile may be consistent in terms of one measure but inconsistent for another. We shall follow convention in assuming that the poverty profile should reveal differences in command over the basic consumption needs for good health and normal activities.

The appeal of this type of consistency may be at odds with another idea that is often desirable: that the choice of the basic-needs bundle should reflect local perceptions of what consritutes "poverty" in each subgroup of the poverty profile. For brevity, ler us call this "specificity". One may interpret this as either a separate goal to "basic-needs consistency", or as another way of defining consistency, by which the measure of individual well-being is broadened to include feelings of relative deprivation. For example, Sen (1987) proposes a definition of "poverty" as the lack of certain "capabilities", such as being able to participate with dignity in the society around one. The capabilities are absolute, but the commodities needed are relative.

There is evidence of such specificity. Studies of subjective poverty lines reveal systematic relationships between perceptions of what constitutes poverty and characteristics of the perceiver (Kapteyn et al., 1988). One also observes a strong positive relationship between country poverty lines and average consumption across countries (Ravallion et al., 1991). Indeed, amongst developed countries it is not uncommon to find poverty lines which have an elasticity of unity with respect to the average standard of living, in which case most poverty measures will be independent of absolute 
levels of living, but will depend entirely on relative inequalities. ${ }^{t}$

Clearly there can be a conflict between consistency and specificity. Basic-needs consistency requires that the poverty lines used imply the same command over basic needs within the domain of the poverty profile; the poverty lines may well be alien to the average standards of living of some subgroups. In proposing basic-needs consistency as a test for a poverty profile we do not claim that this is all that marters. If one is after a purely descriptive account of poverty incidence by local. perceptions, such consistency will have little appeal. However, one can readily imagine other circumstances in which an insistence on respecting :he specificity of Incal poverty lines could yield absurd policy implications. For example, while the official estimates of poverty incidence in the USA and Indonesia around 1990 are at about the same level (14-15\% of the populations are deemed poor), one would be loath to say that aid from the USA to Indonesia should thus cease; there are clearly many people who are not deemed poor in Indonesia who would be considered so in the USA. The measurement choice must ultimately rest on the purpose of the poverty profile.

\section{The Cost of "Basic-Needs"}

We follow common practice in taking "poverty" to mean a lack of command over "basic consumption needs", and the "poverty line" to be the cost of those needs. One method of implementing this definition is to stipulate a consumption bundle deemed to be adequate for basic consumption needs, and then to estimate its cost for each of the subgroups being compared in the poverty profile; this is the approach of Rowntree (1901) in his seminal study of poverty in York in 1899 , and it has been followed since in a number of studies for both developed and developing countries (an example is Thomas's (1980) work on the regional poverty profile in Peru). We call this the "cost-of-a-basic-needs" (CBN) method of setting poverty lines.

1 This holds for all poverty measures which are invariant to scale, in that the measure is homogeneous of degree zero in the poverty line and the mean: see Ravallion (1993) for further discussion. 
One can interpret this method in two quite distinct ways. It can be interpreted as the "costof-utility", though only under quite special assumptions about preferences. (If one uses the cost of a given basic-needs bundle then one must assume that utility-compensated substitution effects are zero. That is a restrictive assumption, though possibly less so for the poor. If it holds then the estimated CBN - normalized by its value for some reference - is a utility-consistent cost-of-living index. On such indices see, for example, Deaton and Muellbauer, 1980.) By the second interpretation, the definition of "basic needs" is deemed to be a socially-determined normative minimum for avoiding poverty, and the cost-of-basic-needs is then closely analogous to the idea of a statutory minimum wage rate. No attempt is made to assure that utility rankings and poverty rankings coincide under this interpretation; a person might (for example) be deemed "poorer" in state A than state $B$ even if she prefers $A$ to $B$.

However, in practice the idea of respecting consumer choice has still influenced the second interpretation of the CBN approach in important ways. The criterion for defining poverty is rarely that one attains too little of each basic need. ("Undernutrition" is viewed as a distinct concept to "poverty".) Rather, it is that one cannot "afford" the cost of a given vector of basic needs. The definition of "afford" may or may not respect consumer choice. Early attempts to determine the minimum cost of achieving the basic-needs vector at given prices ignored preferences. However, the resulting poverty lines were often so alien to consumer behavior that their relevance as a basis for policy was doubtful (see Stigler's, 1945, estimates of the minimum cost of a nutritionally adequate diet). Instead, current practices aim to anchor the choice more firmly to existing demand behavior. Amongst the (infinite number of) consumption vectors which could yield any given set of basic needs, one is chosen which is consistent with choices actually made by some relevant reference group. Poverty is then measured by comparing actual expenditures to the CUN. (There is also an issue about whether it should be expenditures or incomes; Ravallion, 1993, discusses this issue and we shall not go into it further here.) A person is not deemed poor who consumes less food 
(say) than the stipulated basic needs, but could do so on rearranging her budget allocation.

\section{Spending to Reach Basic Food Needs}

Implementation of the CBN method poses a number of problems. A degree of arbitrariness in defining basic needs is inevitable, though it is not obvious that consistent poverty-rankings will be affected much by that choice. Another problem is that cross-sectional (and sometimes even intertemporal) price data are incomplete or unreliable; this is particularly problematic for non-food goods. Achieving consistency - even in terms of the most basic consumption needs - may then be difficult.

A popular method of setting poverty lines tries to avoid these problems, while still anchoring the poverty line to the most basic consumption need: food energy requirements. The main alternative to the CBN method proceeds by finding the consumption expenditure or income level at which a person's typica: food energy intake is just sufficient to meet pre-determined food energy requirement. We shall call this the "food-energy-intake" (FEI) method. The method has been used in numerous countries; for example see Dandekar and Rath (1971), Osmani (1982), Geer and Thorbecke (1986), Paul (1989), Ahmed (1991), and Ercelawn (1991).

Notice that the FEI method is also aiming to measure consumption poverty, rather than undernutrition. If one wanted to measure undernutrition, one would simply look at nutrient intakes relative to requirements, and not incomes or consurnption expenditures. What the FEI method is aiming to do is in principle the same as the CBN method: to find a monetary value of the poverty line at which "basic needs" are met.

In practice, both the CBN and FEI methods anchor the definition of basic needs to food energy requirements. Setting those is itself problematic. (Requirements vary across individuals and over time for a given individual. An assumption must also be made about activity levels which determine energy requirements beyond those needed to maintain the human body's metabolic rate at rest.) However, this issue takes us beyond our present scope. (For an attempt to deal explicitly 
with the implications of un-observed variability in nutritional requirements see Ravallion, 1992b). We shall follow common practice in assuming that a single nutritional requirement for a typical person is already set. For the present inquiry, the key difference between methods is in how food energy requirements are mapped into the expenditure space.

In this respect, the FEI method is computationally far easier than the CBN method. A common practice is simply to calculate the mean income or expenditure of a sub-sample of households whose estimated caloric intakes are approximately equal to the stipulared requirements. More sophisticated versions of the method use regressions of the empirical relationship between food energy intakes and consumption expenditure. These can be readily used (numerically or explicitly) to calculate the FEI poverty line. Figure 1 illustrates the method for two stylized subgroups "urban" and "rural". On the vertical axis one has food-energy intake, which is plotted against total consumption expenditure on the horizontal axis. A line of "best fit" within each sector is indicated; this is the expected value of caloric intake at a given value of total consumption. By simply inverting this line, one then finds the total consumption expenditure at which a person typically attains the stipulated food-energy requirement within each sector. ${ }^{2}$ The method automatically includes an allowance for both food and non-food consumption - thus avoiding the tricky problem of determining what exactly basic needs are for these gooos - as long as one locates the total consumption expenditure at which a person typically attains the caloric requirement. It also avoids the need for price data; in fact, no explicit valuations are required. Thus the method has a number of practical advantages, as proponents have noted (Osmani, 1982; Greer and Thorbecke, 1986; Paul, 1989).

Ostensibly then, the FEI method offers hope of constructing a poverty profile consistent with the attainment of basic food needs, and of doing so with relatively modest data requirements. But

2 Some versions of the FEI method regress (or graph) nutritional intake against consumption expenditure and invert the estimated function, while others avoid this step by simply regressing consumption expenditure on nutritional intake. These two methods need not give the same answer, though the difference is not germane to our present interest; either way the following points apply. 
if we are to use this method for informing policies aimed at reducing poverty in terms of basicconsumption needs we must also ask: how closely will the FEI method approximate a consistent poverty profile, in that people with the same command over those needs are treated the same way?

A key point to note is that the relationship between food energy intake and total consumption expenditure is very unlikely to be the same across the domain of any poverty comparison, but will shift according to differences in tastes, activity levels, relative prices, publicly-provided goods or other determinants of affluence besides consumption expenditure. And there is nothing in the FEI method to guarantee that these differences are ones which would be considered relevant to poverty comparisons. The following are examples:

(i) To the extent that prices differ between urban and rural areas (due, say, to transport costs for food produced in rural areas) one will want to use different nominal poverty lines. However, relative prices can also differ and (in general) this will alter demand behavior at given real expenditure levels (nominal expenditures deflated by a suitable cost-of-living index). The prices of certain nor-food goods tend to be lower relative to foods in urban areas than rural areas, and their retail outlets also tend to be more accessible (so the full-cost, including time is even lower) in urban areas. This may mean that the demand for food and (hence) food energy intake will be lower in urban areas than rural areas, at any given real expenditure level. But this does not, of course, mean that urban households are poorer at a given expenditure level.

(ii) Activity levels in typical urban jobs tend also to require fewer calories to maintain body weight than do rural activities. (Compare the stipulated food-energy requirements for activities such as agricultural labor with factory work, as given in WHO, 1985.) Again food intakes will tend to be lower at a given real expenditure, but this should clearly not be taken as a sign of poverty.

(iii) Tastes may differ systematically. At given relative prices and real total expenditures, urban households may simply have more expensive food tastes: they eat more rice and less cassava, more animal protein and less foodgrain, or simply eat out more often. Thus they pay more for each 
calorie, or (equivalently) food energy intake will be lower at any given real expenditure level. Again, it is unclear why we would deem a person who chooses to buy fewer and more expensive calories as poorer than another person at the same real expenditure level.

In each of these cases, the real expenditure level at which an urban resident typically attains any given caloric requirement will tend to be higher than in rural areas. And this can hold even if the cost of basic consumption needs is no different between urban and rural areas. The FEI method may thus build-in differences between the poverty lines which are not related to the agreed definition of the standard of living. Consider Figure 1 again. The urban poverty line is $z_{u}$ while the rural line is $z_{r}$. However, there is nothing in the method to guarantee that the differential $z_{\mathrm{u}} / z_{\mathrm{r}}$ equals the differential in the cost-of-basic needs between urban and nural areas. An unwarranted differential in poverty lines may then appear, and the poverty profile will be inconsistent in terms of command over basic consumption needs.

In defense of the FEI method, it might be argued that one should use higher poverty lines in better-off areas, to reflect the "relative deprivation" of the poor. For example, the difference in food tastes described in point (iii) may be due to genuine feelings of relative deprivation in urban areas experienced by a poor person who does not conform with prevailing tastes in cities.

One could argue for and against the judgement that such feelings of relative deprivation should be included in an assessment of absolute poverty; if one takes the objective of the policies (which are to be informed by the poverty profile) to be the elimination of absolute poverty - in terms of attainment of basic consumption reeds - then relative deprivation will have zero weight. But even if we did want to attach a positive weight, it is entirely unclear whether the FEI method is putting the right value on relative deprivation; we simply do not know how important this is to the poor, in whict case it is worrying that the FEI method does so implicitly. In short, we do not know in what sense the FEI method is "consistent". A more transparent approach would be to identify what extra money one assumes would be needed to compensate the poor in "rich" areas for their relative 
deprivation, and add this to the cost-of-basic needs.

These problems are quite worrying when there is mobility across the subgroups of the poverty profile, such as migration from rural to urban areas. Suppose that - as the above discussion has suggested may well happen - the FEI poverty line has higher purchasing power in terms of basic needs in urban areas than rural areas. Consider someone just above the FEI poverty line in the rural sector who moves to the urban sector and obtains a job there generating a real gain less than the difference in poverty lines across the two sectors. Though that person is better off - in that she can buy more of all basic needs, including food - the aggregate measure of poverty across the sectors will show an increase, as the migrant will now be deemed poor in the urban sector. Indeed, it is possible that a process of economic development through urban sector enlargement, in which none of the poor are any worse off, and at least some are better off, would result in a measured increase in poverty. Similar points can be made concerning the use of the FEI method in making poverty comparisons over time; it is entirely possible that the method will show rising poverty rates over time even if all households have higher real incomes.

In summary, a priori considerations lead one to suspect that a FEI-based poverty profile could deviate from one which is consistent in terms of the household's command over basic needs. By anchoring poverty lines to the observed empirical relationship between food-energy intake and total consumption expenditure within each subgroup, the FEI method can estimate poverty lines without data on prices. However, this particular anchor is going to shift across the poverty profile in ways which have little or nothing to do with differences in command over basic consumption needs. Nor is it clear if there is any meaning ful sense. in which FEI poverty lines can be considered "consistent" in other "non-basic" needs.

\section{An Example from Indonesia.}

Indonesia's Central Bureau of Statistics (Biro Pusat Statistik: BPS) uses the FEI method for 
constructing its poverty lines (see BPS, 1990, 1992). ${ }^{3}$ Their urban poverty line for 1990 of Rp. 20,614 is the estimated expenditure level at which a typical urban resident reaches the pre-determined mean food-energy requirement of 2100 calories per person per day; the corresponding rural expenditure to reach the same caloric intake is Rp. 13,295. The Indonesian method is only one example of a common practice, and we are focusing on this country here in large part because the government expressed interest in the properties of this method, and alternatives.

As is typically the case in developing countries, the urban relationship between food-energy intakes and total expenditures is different to the rural one, with higher intakes at given consumption expenditure level in rural areas. This could well reflect one or more of the factors discussed above. The concern here is that these factors may lead to poverty lines which entail different standards of Iiving in different subgroups of the poverty profile. In principle, there are two equivalent ways one can address this concern: i) one can look at the typical consumption vectors at the FEI poverty lines and ask if they imply the same standard of living, or ii) one can deflate the nominal poverty lines by an appropriate cost-of-living index, normalizing for differences in the cost of a given standard of living. In practice, neither is straightforward. In this section we offer some casual observations; later we will present new evidence on spatial differenc:s in the cost-of-living facing the poor.

What do people in a neighborhood of the BPS poverty lines typically consume? Table 1 gives our calculations of the mean consumption vectors in a region of Rp. 500 above and below the BPS poverty lines, from the data tapes of Indonesia's National Socio-Economic Survey (SUSENAS) for 1990 . Both bundles yield 2100 calories per person per day. However, the rural bundle derives a higher share of its calorific value from the staple foodgrains. Also, the urban bundle has higher consumptions of the "superior" food staple (rice), and lower consumptions of the "inferior" staples

3 For an overview of the various approaches to poverty measurement used in the Indonesian literature see World Bank (1990) and Booth (1992). Contributions to that literanure have been made by Sayogyo and Wiradi (1985), Bhanoji Rao (1984), BPS (1989), and Asra (1989). Mention should also be made of the antecedents in the literature on poverty in India; see Bardhan (1970) and Dandekar and Rath (1971). . 
(corn and cassava). Similarly the urban bundle is more generous in more expensive vegetables (tomatoes) with less of the cheaper ones (cassava leaves) than the rural bundle. The urban bundle also has higher consumptions of meat and chicken, and considerably higher expenditures on food and drink consumed outside the home. Which of these two consumption bundles would one prefer, ignoring the difference in their cost? Clearly one cannot answer this question in the abstract (there are theoretically admissible preferences which could go either way). But we would be surprised if the vast majority of Indonesians did not give the urban bundle as their answer.

The difference in the relationship between food-energy intake and total spending between urban and rural areas - and hence in the poverty lines - is so large that, at any given food-energy requirement level, the urban FEI poverry line exceeds the rural line by a magnitude which is sufficient to imply an estimated head-count index of poverty which is greater in the urban sector than the rural sector. This is illustrated in Figure 2, which gives the cumulative distribution of nominal consumption per person in each of urban and rural areas of Indonesia in 1990, which we have estimated from the data tapes of Indonesia's National Socio-Economic Survey (SUSENAS) for 1990. At the BPS (1992) rural poverty line for 1990 one finds that about $14 \%$ of the rural population is poor. At the BPS urban poverty line we find that $17 \%$ of the urban population is poor.

But notice that, at any given poverty line (fixed across both sectors) in Figure 2, the proportion of the rural population deemed poor is higher than that of the urban population. And this holds wherever one draws that poverty line. If there is no difference in cost-of-basic-needs between urban and rural areas then this implies more poverty in rural areas no matter where one draws the poverty line, or what poverty measure one uses (within a broad class; see Atkinson, 1987). However, there clearly are cost-of-living differences between urban and rural areas; and so this conclusion need not hold, given that the distributions iri Figure 2 are not adjusted for those differences. We shall amempt to do so later in this paper, but first it is of interest to ask: What is the critical poverty line differential needed for a reversal of the sector poverty ranking? It is easy 
to calculate numerically that, as long as the urban poverty line is no more than $45 \%$ higher than the rural poverty line, the head-count index will be higher in rural areas. (This is the same - to the nearest integer - whether one uses the BPS urban poverty line as the reference or their rural line.) But with the BPS differential of $55 \%$ we get the opposize conclusion.

Unfortunarely, no satisfactory spatial cost-of-living index is available for Indonesia. Markets may not be perfectly integrared spatially, but it is difficult to believe that existing transport costs and barriers to trade in Indonesia could yield a $45 \%$ differential in the prices of basic consumption items between urban and rural areas. Ravallion and van de Walle (1991) estimated a behavioral cost-ofliving index for Java using a demand model estimated on 1981 SUSENAS data, which allowed for housing cost äifferences (after controlling for observable differences in housing quality), and rice price differences. For the poor, the estimated cost-of-living difference berween urban and rural areas was about $10 \%$, though it was slightly over $20 \%$ between Jakarta and rural areas. Though clearly restricted in both commodity and geographical coverage, this result does not suggest:that urban-rural cost-of-living differences are as high as the differential built into the BPS poverty lines, or as high as the critical differential needed for the sectoral poverty ranking obtained by BPS.

\section{An Alternative Approach}

In the following sections we will examine more closely the robustness of Indonesia's poverty profile to measurement assumptions. As a bench-mark for comparison with the existing poverty profile based on the FEI method, we shall construct our own profile using a version of the CBN method. We do not claim our method to be ideal. but only that it is a credible alternative which is implementable with the available data.

The first problem in doing so is setting the basic-needs bundle. Nutritional requirements are a defensible anchor for the food bundle and, when the composition of local food diets is also taken as given, the food component of a CBN poverty line is fully determined. Non-food basic needs are 
a bigger problem, which we discuss further below.

The second problem is costing the basic-needs bundle. It is surprisingly rare for statistical agencies to provide spatial costs-of-living indices, analogous to the usual Consumer Price Indices (CPI) used for inter-temporal cost-of-living comparisons. ${ }^{4}$ For some time now, the lack of a suitable spatial price index for Indonesia has clouded efforts to compare living standards across the archipelago (Booth, 1992). The paucity of reliable price data - particularly for non-food goods severely constrains attempts to form a consistent regional poverty profile.

Our approach to estimating CBN poverty lines for Indonesia - to be compared with the existing FEI lines in the next section - incorporates two basic refinements to most past versions of the CBN method. The first is that we not only anchor the food component to the stipulated food energy requirement, we also adjust its composition to accord with observed diets of the poor. The second is that we adopt a new method of setting non-food basic needs consistent with consumption behavior of those who can just afford their basic food needs.

However, as we are concerned more with the way these methods rank subgroups in the poverty profile, we will calibrate the CBN method to yield a similar aggregate incidence of poverty as BPS's FEI method. In particular, our CBN method will use the same specification of nutritional requirements. (As we have already noted, there is an inherent arbitrariness in setting food energy requirements, but this is a common problem to both methods. We will test the robustness of the CBN-based poverty measures to the level of the poverty line.) And we will chose the reference group for specifying tastes to accord with the estimates of poverty incidence obtained by BPS. Our objective is not to come up with an alternative estimate of the extent of aggregate poverty incidence in Indonesia, but rather to compare how these two methods rank subgroups, as this is what matters most to the policy implications.

4 CPI's are sometimes available by region. However, they are rarely valid for making spatial comparisons, since they are indexed to a common value in the base date for all regions. 


\section{The Food Poverty Line}

First we specify a reference household deemed to be typical of the poor. We chose that household to have the mean values of all relevant variables for the poorest $15 \%$ of the Indonesian population, when ranked according to expenditure per capita. This is the same group of persons deemed to be poor in 1990 by BPS (1992). The consumption pattern of this reference household becomes the "anchor" for the subsequent stages.

Next we set the poverty line in each region. A person is deemed poor if she lives in a household which cannot afford the cost of a reference food bundle, chosen to yield adequate food energy intake, consistent with the typical diet of those deemed poor. Following past practice for Indonesia, we set the food energy requirement at 2100 calories per person per day, again following BPS $(1990,1992)$. The judgement about whether or not the household can afford the reference food bundle is based on the household's consumption expendiure on all goods and services.

More formally, let $x^{r}$ denoze the actual food consumption vector of the reference group of households. The corresponding caloric values are represented by the vector $k$, and the food energy intake of the reference household is then $k^{r}=k x^{\prime}$. The recommended food energy intake is $k^{*}$. The reference food consumption bundle used in constructing the poverty line is then given byx*

such that $k^{*}=k x^{*^{\prime}}$. There are, of course, infinitely many possible consumption vectors that would yield $k^{*}$. The particular composition of $x^{*}$ used in constructing the poverty line is obtained by multiplying every element of $x^{r}$ by the constant $k^{*} / k^{r}$. Thus the relative quantities in the diet of the poor are preserved in setting the poverty line.

Having selected the bundle of goods, we then value it at local prices in each region. In principle this is straightforward, though in practice there are often problems of matching the price data with the budget data used in constructing the reference food bundle. There is nothing of any 
general interest that can be said about those problems, so we refer interested readers to Bidani and Ravallion (1993) which describes the method in greater detail.

\section{The Allowance for Non-Food Goods}

In principle, one could proceed the same way for non-food goods i.e., set a bundle of such goods, and cost that bundle separately in each region and sector. However, certain considerations militate against that approach in the case of non-food goods. While food energy requirements are the obvious anchor for food consumption, there is no analogous basis for setting basic non-food consumption. Furthermore, as is common for most developing countries, non-food prices are difficult to monitor reliably (indeed, prices for more than a few non-food goods are rarely available from staristical agencies).

The problem is how one can best allow for differences in the basic non-food goods needed to achieve the same standard of living in the various sectors or regions being compared. Past approaches to setting poverty lines have tried to anchor the allowance for non-food goods to the consumption be'lavior of the poor, but in ways which are likely to create biases in the poverty profile. For example. dividing by mean food share of the poorest $20 \%$ (say) in each subgroup will typically entail higher real poverty lines in richer regions. The idea of anchoring the allowance for non-food goods to the consumption behavior of the poor does, however, make sense; the issue is more one of deciding at what point in the distribution of consumption amongst the poor one should focus on. Here we implement the method suggested in Ravallion (1993, Appendix 1).

An appealing test for defining a "basic non-food need" is that one is willing to forgo a basic food need in order to obtain that good. We can thus ask: what level of non-food spending will people allow to displace basic food spending, as embrdied in the food poverty line? There will undoubtedly be some displacement of basic food spending over a range of consumption levels. Even those households whose total consumption expenditure is below that required to meet their nutritional 
requirements with the traditional diet will almost certainly spend something on non-food goods. The berter measure of basic non-food spending is to look at how much is spent on non-food goods by households who are capable of reaching their nutritional requirements, but choose not to do so. Of course, quite large sums might be spent by some households on non-food goods, even though nutritional requirements are not being adequately met. One may not want to identify all such households as "poor". There will also be some variation in spending patterns at any given budget level, such as due to measurement errors or random differences in tastes. Given this heterogeneity, a more reasonable approach is to ask: what is the typical value of non-food spending by a household who is just capable of reaching food requirements? As long as non-food is a normal good, this will also equal the lowest level of non-food spending for households who are capable of acquiring the basic food bundle. It can thus be considered a minimal allowance for non-food goods.

This definition of the basic non-food component can be implemented quite easily with readily available data. To illustrate, let us assume that food spending increases with total spending, with a slope less than unity, and decreases as total spending increases (as implied by - but not implying Engel's Law that the income elasticity of demand for food is less than unity). This is depicted in Figure 3. (This can be thought of as a regression line, giving the expected value of food spending at any given value of total spending.) Let us also assume that there is a unique expendinure needed to reach nutritional requirements, as indicated in Figure 3. This is the food poverty line, $z^{f}$. Amongst those households who can afford to reach their nutritional requirements (with given tastes) the lowest level of non-food spending is given by the distance NF in Figure 3, all of which displaces basic food spending. This then is the basic level of non-food spending. The combined poverty line is then given by $z$ ( $z^{f}$ plus $N F$.

The value of NF can be estimated as follows. We begin with a demand function for food, representing the food share as a linear function of the log of total spending (food plus non-food) relative to the cost of basic food needs (augmented for other relevant variables: see the Appendix for 
details on the derivation of the estimared model). For household $\mathrm{i}$ in region $\mathrm{j}$ :

$$
s_{i j}=\alpha_{j}+\beta_{j} \log \left(y_{i j} / z_{j}^{f}\right)+\text { error term }{ }_{i j}
$$

where $s_{i j}$ is the share of total expenditure $y_{i j}$ which is devoted to food, $z_{j}^{f}$ is the cost of basic food needs, and $\alpha_{j}, \beta_{j}$ are paramerers to be estimared. The value of the intercept $\alpha_{j}$ estimates the average food share of those households who can just afford basic food needs, i.e., those for whom $y_{i j}=z_{j}^{f}$. (The same is true if one adds a term in the squared value of $\log \left(y_{\mathrm{ij}} / z_{\mathrm{j}}^{\mathrm{f}}\right)$, which will probably allow a better fit to the data as it permits the income elasticity of demand for food to exceed unity at low values of $y$ ). The poverty line is then given by:

$$
z_{j}=z_{j}^{f} \cdot\left(2-\alpha_{j}\right)
$$

In words, the poverty line is obtained by scaling up the food poverty line, the proportionate increase being given by the estimared non-food budget share at the food poverty line.

Notice that this method does not insist that the non-poor actually spend enough on food to buy the nutritionally-adequate food-bundle. (That would entail a higher poverty line, where $z^{f}$ intersects with the "food spending" curve in Figure 3.) Rather it only insists that they are capable of doing so. as discussed in section 2. Thus our method deems a person to have escaped poverty if, and only if, she can afford the stipulated basic consumption needs; whether in fact she also chooses to do so is another matter.

\section{The Poverty Measures}

Having estimated the regional poverty lines, the poverty measures are then estimated for each region, and aggregated to the national level. Three standard poverty measures are used in this sudy:

i) The head-count index $(H)$, given by the percentage of the population who live in households with a consumption per capita less than the poverty line. This measure has the advantage 
that it is easy to interpret, but it tells us nothing about the depth or severity of poverty.

ii) The povertv gap index (PG), defined by the mean distance below the poverty line expressed as a proportion of that line (where the mean is formed over the entire population, counting the non-poor as having zero poverty gap). (This is the Foster, Greer and Thorbecke, 1984, definition of the poverty gap index, which has advantages over the "income-gap ratio", obtained when the mean is only formed over those who are poor: for further discussion see Ravallion 1993).

iii) The Fostēr-Greer-Thorbecke $P_{2}$ measure, defined as the mean of the squared proportionate poverty gaps (again the mean is formed over the entire population, counting the non-poor as having zero poverity gap). Unlike the poverty gap index, this measure reflects the severity of poverty, in that it will be sensitive to inequality amongst the poor.

\section{Comparing Methods}

We shall now compare the methods described in the previous two sections on data for Indonesia. For the FEI method, we rely on the results reported in BPS (1992), based on the 1990 SUSENAS. The BPS poverty lines were constructed by the method described in section 2 , using graphs of mean food energy intake against consumption expenditure per person, with different graphs for each province of Indonesia, and separately for urban and rural areas. For the CBN method we follow the approach outlined in the previous section, implemented on exactly the same data set. For both methods, average food-energy requirements are set at 2100 calories per person per day.

In both cases, the data tapes of the 1990 SUSENAS were used in estimating the poverty measures for each region. The 1990 SUSENAS gives consumption data for a stratified sample of 45,000 households, surveyed in January of that year. In all estimations, the inverse sampling rates estimared by BPS were used to obtain un-biased population estimates. We shall oniy summarize the salient features here, before discussing the comparison; Bidani and Ravallion (1993) documents the results in far greater detail. 
Our reference food bundle for the CBN method includes 31 foods, allowing slightly more than 400 grams of food-grains (plus cassava) per person per day. plus small amounts of fresh fish, meats, eggs and a range of local vegetables, fruits, condiments and spices. Of the 2100 calories per person per day which this bundle yields, $81 \%$ came from food-grains and cassava. The average cost of the reference food bundle in January 1990 was Rp. 13,028. In urban areas the average cost was Rp. 14,043, while in rural areas it was Rp. 12,581. (Bidani and Ravallion, 1993, give the results by region.). Urban food prices were, on average, $12 \%$ higher than rural food prices. By contrast, the estimated cost of non-food basic needs was $44 \%$ higher in urban areas. With the allowance for non-food basic needs, the mean poverty line in urban areas was $R p 18,519$, and $R p 15,693$ in rural areas, giving an overall differential of $18 \%$ in the poverty lines across the two sectors.

\section{Poverty Profiles by each Method}

Table 2 reports the aggregate poverty measures for Indonesia and for the urban and rural areas separately, using both the CBN and FEI methods. (To help assess the sensitivity of the CBN method to the definition of "basic needs" we also give some key results for the food component only.) The national poverty measures by the FEI method lie between those we have estimated for the food poverty line and the total poverty line by the CBN method, and are appreciably lower than the latter. However, the more dramatic difference - and of greater relevance to policy - is that the FEI method shows that urban poverty is higher than rural poverty, a result driven by the far larger (55\%) urban-rural differential in the poverty lines generated by the method, as discussed in section 2. The difference is sufficient to reverse the sectoral rankings for all three poverty measures.

Poverty incidence curves, plotring the percentage of the population consuming less than a given proportion of the poverty line, are shown in Figure 4 for both urban and rural areas, using both the FEI and CBN methods. The results show that the CBN poverty incidence curve for urban areas lies everywhere below that for rural areas, implying that the percentage of the population 
deemed poor for any given poverty line in rural areas is unequivocally higher than for urban areas. Indeed, whatever the poverty line or poverty measure, there is higher poverty in rural areas than urban areas. (This follows from the application of stochastic dominance theory to poverty comparisons; see Atkinson, 1987). By contrast, the poverty lines based on the FEI method imply intersecting poverty incidence curves, though the intersection point is high; up to about $150 \%$ of the poverty line, the FEI mechod gives higher poverty in urban areas. ${ }^{5}$

We present more detailed results by both methods for the head-count index by region in Table 3. (Results for alternative poverty lines and poverty neasures by the CBN method are available in Bidani and Ravalion, 1993. The regional and urban/rural rankings in terms of poverty. are not very sensitive to these choices. BPS, 1992, omits results for some regions, though they are included in the aggregates reported in Table 2.) Using the CBN poverty lines, the incidence of poverty is markedly higher in rural areas than urban areas. The most striking result from Table 3 is the extent of re-ranking thar occurs when one switches from the CBN to the FEI method. This can be seen more clearly in Figure 5 which ranks all regions (provinces split urban-rural) by the head-count index for the FEI poverty lines, and then plots the corresponding CBN estimate of that index. If the two methods agree in their ranking then one would observe a monotonic increasing line (though not necessarily straight) joining all the points. Instead, we see numerous re-rankings. For example, if one asks: "what are the ten poorest regions?" then only three will be in common berween the two methods. The overall rank correlation coefficient is $0.15(n=35)$, which is not significantly different from zero. The two methods are virtually rank-orthogonal.

Figure 5 distinguishes the urban and rural points. As in Table 2, the CBN method generally gives higher poverty measures in rural areas, and re-ranking is evident across provinces within each

5. The poverty deficit curves (given by the areas under the poverty incidence curves) show higher poverty in urban areas up to $300 \%$ of the poverty line (not presented, but available). Thus all poverty measures which are strictly decreasing in consumptions of the poor will show higher poverty in urban areas (Atkinson, 1987). 
of the urban and rural sectors, as well as between them; comparing urban areas only the rank correlation is $0.51(n=18)$, while for rural areas it is $0.17(17)$.

The FEI method gives a better approximation to the province level poverty profile (combining urban and rural areas) based on the CBN poverty lines (Figure 6). Amongst (say) the poorest five provinces by each method there are now four in common (East and West Nusa Tenggara, West Kalimantan, and Central Java). Huwever, a considerable amount of re-ranking occurs amongst other provinces and the overall rank correlation coefficient is $0.39(n=18)$ which is (just barely) significantly different from zero at the $5 \%$ level.

So far we have focused on a single basic-needs bundle and a single poverty measure. How sensitive are poverty rankings to that choice? In Figure 7 we compare results for the "food+non-

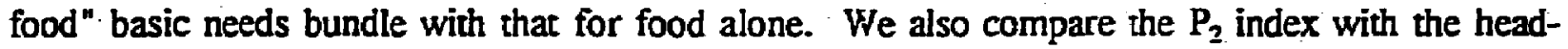
count index (both using the full $C B N$ poverty line). In both cases, there is some re-ranking, but certainly far less than we have seen above. The rank correlation coefficient between the two poverty lines ("food +non-food", versus "food only") is 0.94 ( 0.86 for urban areas, 0.93 for rural areas), while that between the head-count index and $P_{2}$ is 0.95 (0.93 urban, 0.87 rural). Bidani and Ravallion (1993) give results for other combinations of poverty measures and poverty lines; the results are similarly robust.

Within the CBN method, it is also of interest to see how much rankings are affected by the adjustment for spatial differences in the cost of the basic needs bundle (a similar question is posed by Thomas, 1980, for Peru). Separating urban and rural areas, the rank correlation between the head-count index using local poverty lines and that using the national mean poverty line (in effect, using national mean prices) was 0.88 ; at province level it was 0.77 . Again, while there is some reranking, this choice appears to matter far less than that between the CBN and FEI methods.

We also examined Indonesia's poverty profile by the primary sector of employment. Previous studies (Huppi and Ravallion, 1991) on this subject have lacked access to a suitable regional 
price index. Table 4 compares the sectoral profiles derived using poverty lines derived by the CBN and FEI methods. Figure 8 ranks all the sectors (split by urban/rural) by the head-count index of the FEI method and plots the corresponding head-count estimates using the CBN method. The figure shows that the estimates of the urban head-count index derived using the FEI method are higher than those using the CBN method, though the rankings are very similar. Only in two cases are there rerankings. The estimates of the head-count index for rural areas by the FEI method are much lower than those obtained by the CBN method. However, in contrast to urban areas, there is substantial re-ranking in rural areas especially among the sectors that have head-count indices between 5 and $10 \%$ according to the FEI method. These sectors include those employed in the industrial sector as laborere, and in transport (both laborers and self-employed). The overall rank correlation coefficient between the poverty measures using the CBN method and the FEI method is 0.28 (across urban and rural sectors; $n=33)$; comparing urban sectors only it is $0.99(n=16)$ while amongst rural sectors alone it is $0.76(n=17)$.

\section{Why do the FEI and CBN methods differ so much?}

Even purely random differences between two sets of poverty lines could produce such reranking. However, the discrepancies between the two are not random, but are correlated with another key variable determining the poverty profile.

As Table 1 suggested might be the case in the comparison of urban and sural areas, the FEI poverty lines tend to imply a higher standard of living - beyond simply counting calories - in betteroff subgroups. Across regions, both the FEI and CBN poverty lines vary positively with mean consumption, but the FEI lines have a considerably higher elasticity to the mean, thus dampening the response of FEI-based poverty measures to differences in absolute levels of living. Across all regions (pooling urban and rural areas), the least-squares elasticity of the FEI poverty line with respect to mean consumption is 0.86 (with a t-ratio of 15 ); by contrast, the analogous elasticity of 
the CBN poverty line is $0.31(t=6.7)$. (This pattern persists within each of urban and rural sectors separately. ${ }^{\circ}$ ) The basic-needs purchasing power of the FEI line (deflated by the CBN line) has an elasticity of $0.77(t=10)$ with respect to the basic needs purchasing power of the mean. Households in better-off regions are typically reaching the stipulated food energy requirements at higher levels of living. This could be due to any one of the factors described in section 2 .

The elasticity of the FEI lines to the mean is far higher than one finds in the cross-county relationship between the poverty line and average living standards amongst developing countries, and is actually more typical of rich countries; the elasticity of the CBN line is more in line with the slasticity one finds amongst low- and middle-income countries (Ravalion et al., 1991).

In short, the FEI-based measures behave more like relative poverty measures which depend mainly on the differences in Lorenz curves between subgroups in the poverty profile. This appears to be an important factor accounting for the extent of re-ranking. Clearly, if one is aiming to guide policy choices for reducing absolute poverty, the relative insensitivity of the FEI-based measures to differences in absolute levels of living is of concern.

\section{Conclusions}

Poverty comparisons - such as where or when poverty is greatest - typically matter far more to policy choices than aggregate poverty measures - such as how many people are deemed "poor". Thus we should look very closely at how measurement practice affects the empirical profile of poverty. We have discussed the pros and cons of alternative approaches to constructing a poverty profile, and implemented alternative methods on the same data set.

As in many countries, past methods of constructing poverty profiles in Indonesia have used the food-energy-intake method whereby one defines the poverty line as the nominal consumption

6 Across urban areas only, the least squares elasticity of the FEI line to the mean is 0.64 $(t=4.72)$, while for the CBN line it is 0.41 (3.52). For rural areas, the corresponding figures are $1.04(5.98)$ and $0.40(2.71)$. 
expenditure at which a person typically attains a pre-determined food energy intake in each s:bgroup. We argue that this method can yield differentials in poverty lines (such as between urban and rural areas) in excess of the cost-of-living differential facing the poor. Thus the method can mislead policy choices aimed at reducing absolute poverty. For comparison with the food-energy-intake method, we have outlined an alternative "cost-of-basic-needs method", whereby an explicit bundle of foods typically consumed by the poor is valued at local prices, with a minimal allowance for nonfood goods consistent with spending by the poor. While not ideal, this is a conceptually transparent and operational alternative which can be implemented with the available data. We argue that this approach is more likely to generate a consistent poverty profile in that two persons with the same measured standard of living - measured by purchasing power over basic consumption needs - will be treated the same way. Our approach is a refinement of past approaches, retaining some seemingly desirable fearures (such as the concern to respect tastes of the poor), while trying to avoid others (such as the implicit use of a higher real poverty line in richer regions of the same country).

Comparing these two methods for Indonesia, we find that the difference in poverty lines between urban and rural sectors implied by the food-energy-intake method is large enough to cause a rank reversal in all poverty measures between the two sectors; while our alternative cost-of-basicneeds method finds greater poverty incidence, depth and severity in rural areas, the reverse is indicated by the food-energy-intake method. The ranking of regions (each province divided into urban and rural areas) by the two methods has virtually zero correlation. The poverty profile by principal sector of employment is less sensitive to the choice of method (particularly in urban areas). Nonetheless, this case-study, and our supportive a priori arguments, lead us to conclude that policy makers should be very wary of how the underlying poverty measures have been constructed before using the derived poverty profiles to guide the formulation of poverty-reduction policies.

On a positive note, we have found that our alternative poverty profile based on the cost-ofbasic-needs method is fairly robust to a number of other methodological choices, notably changes 
in the composition of the basic needs bundle (determining the overall level of the poverty line), differences in the functional form of the poverty measure, and adjustment for sparial differences in prices. Ironically, while these issues have tended to dominate debates on how to measure poverty. our results suggest that they matter less to poverty rankings and (hence) policy conclusions than the choices made in mapping a given specification of basic needs into monetary poverty lines. 


\section{Appendix}

An estimate of the food Engel curve is needed to make the allowance for non-food consumption using our CBN method (section 3). We postulared that the food share was a function of the food purchasing power of per capita consumption expenditure and the structure of relative (food/non-food) prices. To derive this model, consider the following version of the Almost Ideal Demand System (Deaton and Muellbauer, 1980):

$$
s_{i}=\alpha^{f}+\beta^{f} \ln \left(y_{i} / c_{i}^{g}\right)+\gamma^{f} \ln z_{i}^{f}+\gamma^{f \ln } \ln p_{i}{ }^{n}+\mu_{i}
$$

where $s_{i}$ is the food share for household $i, y_{i}$ is the per capita consumption expenditure of $i, z_{i}^{f}$ is our estimate of the cost of the reference food bundle (i.e., the food poverty line), $p_{i}^{n}$ is the price of a composite bundle of non-food goods, and the cost of zero utility is given by:

$$
\begin{gathered}
\ln c_{i}^{0}=\alpha_{0}+\alpha^{f} \ln z_{i}^{f}+\alpha^{n} \ln p_{i}^{n} \\
+\frac{1}{2}\left[\gamma^{f}\left(\ln z_{i}^{f}\right)^{2}+2 \gamma^{f n} \ln z_{i}^{f} \ln p_{i}^{n}+\gamma^{n n}\left(\ln p_{i}^{n}\right)^{2}\right]+x_{i} \pi
\end{gathered}
$$

where $x_{i}$ represents a vector of other exogenous variables (for example demographic variables). Under the parameter restrictions implied by the fact that the budget shares must sum to unity $\left(\alpha^{f}+\alpha^{n}=1\right)$, the demands must be homogeneous of degree zero in prices $\left(\gamma^{f}+\gamma^{n f}=0, \gamma^{f n}+\gamma^{n n}=0\right)$ and the Slutsky matrix must be symmetric $\left(\gamma^{/ n}=\gamma^{n f}\right)$, this can also be written in the form:

$$
s_{i}=\alpha^{f}+\beta^{f} \ln \left(\gamma_{i} / z_{i}^{f}\right)+\delta_{i} \ln k_{i}+\mu_{i}
$$

where

$$
\begin{gathered}
\ln k_{i} \equiv \ln \left(p_{i}^{\pi} / z_{i}^{f}\right) \\
\delta_{i}=\gamma^{f f}-\beta^{f}\left(1-\alpha^{f}+\gamma^{f} k_{i} / 2\right)
\end{gathered}
$$


Since non-food prices are unavailable, we introduce province/(urban/rural) dummy variables to capture differences in relative prices, in the level of public services and other differences across regions that are we do not observe. By adding an additional random error term we obtain the following specificatior:

$$
s_{i}=\alpha+\beta_{0} \ln \left(y_{i} / z_{i}^{f}\right)+\sum_{j=1}^{n} \phi_{j} D_{i j}+x_{i} \pi+v_{i}
$$

We tested this against some ad hoc alternatives. One was to include the log of food price as a separate regressor; the coefficient on this variable was insignificant. However, we found that a significant improvement in fit could be obtained by adding a term in the squared value of $\ln \left(y_{i} \mid p_{i}^{5}\right)$. The vector of demographic variables includes the age-sex composition of the household in the age groups $<4,5-9,10-14,15-59$ and $60+$ years; dummy variables for the education, marital staus and sex of the household head and the number of indivituals employed in the household. We then obtained the following estimate of this specification of the Engel curve on the 45,000 households in the SUSENAS sample is as follows. (Absolute t-ratios in parentheses. This is a weighted least squares estimate, assuming that the error variance is proportional to the inverse sampling rate for each household. Tnis gave a slight improvement in overall fit.)

$s=\begin{gathered}0.67-0.061 \log \left(y / z^{f}\right)- \\ (127.5)(28.3)\end{gathered}$

$$
\mathrm{R}^{2}=0.489
$$

We use this equation to compute the poverty line, $z$, for each region using the mean demographics of the poorest $15 \%$ nationally. Hence, $z_{j}=z_{j}^{f}\left(2-\alpha_{j}\right)$ where $\alpha_{j}=\hat{\alpha}+\bar{x}_{(1)}{ }^{\hat{\pi}}+\hat{\phi}_{j}$ and $\bar{x}_{(1 s)}$ is the mean of the demographic variables of the poorest $15 \%$ nationally. 


\section{References}

Ahmed, Taher Uddin 1991, "Poverty in Bangladesh", in Proceedings of the Workshop of Dissemination of Current Statistics, Dhaka: Bangladesh Bureau of Statistics.

Asra, Abuzar 1989, "Poverty Trend in Indonesia 1970-1987", Ekonomi Dan Keuangan Indonesia Vol. 37. pp.379-392.

Atkinson. Anthony B., 1987. "On the Measurement of Poverty". Economerrica, Vol.55, pp.749-64.

Bardhan, Pranab K., 1970, "On the Minimum Level of Living and the Rural Poor", Indian Economic Review Vol. 5, pp. 129-136.

Bidani, Benu and Martin Ravallion 1993, "A New Regional Profile of Poverty in Indonesia", Bulletin of Indonesian Economic Studies, forthcoming-

Biro Pusat Statistik (BPS) 1989. "Pengeluaran Untuk Konsumsi Penduduk Indonesia 1989", Biro Pusar Statistik, Jakarta, Indonesia.

1990, "Perkembangan Mingguan", Biro Pusat Statistik, Jakarta, Indonesia.

1991, "Harga Konsumen Beberapa Barang Dan Jasa Di Seluruh Ibukota Propinsi Indonesia 1989-1990", Biro Pusat Statistik, Jakarta, Indonesia.

Bíro Pusat Statistik, Jakarta, Indonesia.

1992, "Kemiskinan dan Pemerataan Pendapatan di Indonesia 1976-1990",

Booth. Anne 1992, "Counting the Poor in Indonesia", Working Paper 17, Department of Economics, School of Oriental and African Studies, University of London.

Dandekar, V.M., and N. Rath. 1971. Poverty in India. Pune: Indian School of Political Economy.

Deaton, Angus, and John Muellbauer 1980, Economics and Consumer Behavior, Cambridge: Cambridge University Press.

Ercelawn. Aly 1991, "Absolute Poverty as Risk of Hunger: Norms, Incidence, and Intensity for Rural and Urban Pakistan", mimeo, Applied Economics Research Centre, University of Karachi.

Esmara. Hendra 1986, Perencanaan dan Pembangunan di Indonesia. Jakarta: Gramedia.

Foster. James. J. Greer. and Erik Thorbecke 1984, "A Class of Decomposable Poverty Measures". Econometrica, Vol.52. pp. 76l-66.

Foster. James, and A. F. Shorrocks 1991, "Subgroup Consistent Poverty Indices", Econometrica, Vol. 59. pp. 687-709.

Greer. J., and Erik Thorbecke 1986, "A Methodology for Measuring Food Poverty Applied to Kenya". Journal of Development Economics Vol. 24. 
Huppi, Monika, and Martin Ravalion 1991. "The Sectoral Structure of Poverty During an Adjustment Period. Evidence for Indonesia in the Mid-1980s", World Development Vol.19, pp. 1653-1678.

Kapteyn, Arie, Peter Kooreman, and Rob Willemse. 1988, "Some Methodological Issues in the Implementation of Subjective Poverty Definitions", The Journal of Human Resources Vol 23, pp. 222-242.

Osmani, Siddiqur, 1982, Economic Inequality and Group Welfare Oxford: Oxford University Press.

Paul, Satya, 1989, "A Model of Constructing the Poverty Line", Jcurnal af Development Economics Vol. 30, pp. 129-144.

Rao, V.V. Bhanoji, 1984, "Poverty in Indonesia, 1970-1980: Trends, Associated Characteristics and Research Issues", mimeo, World Bank.

Ravalion, Martin, 1992, "Does Undermutrition Respond to Incomes and Prices? Dominance Tests for Indonesia", World Bank Economic Review Vol. 6, pp: 109-124.

1993, Povertv Comparisons Chur, Switzerland: Harwood Academic Press Fundarsentals of Pure and Applied Economics Volume 56.

Ravallion, Martin, Gaurav Datt, and Dominique van de Walle 1991, "Quantifying Absolute Poverty in the Developing World", Review of Income and Wealth, Vol.37 (1991), pp. 345-361.

Ravallion, Martin and Dominique van de Walle 1991, "Urban-Rural Cost of-Living Differentials in a Developing Country", Journal of Urban Economics Vol. 29, 113-127.

Rowntree, B.S., 190I, Povertv-a Shudv of Town Life. London: Macmillan.

Sen, Amartya K., 1987, The Standard of Living. Cambridge: Cambridge University Press.

Sayogyo; and G. Wiradi 1885. "Rural Poverty and Efforts for its Alleviation in Indonesia: A Sociological Review", WCARRD Follow-up Programme In-depth Studies Series No 18. Food and Agriculural Organization of the United Nations, Rome.

Stigler, G. J. 1945, "The Cost of Subsistence". Journal of Farm Economics Vol.2?.

Thomas, Vinod 1980, "Spatial Differences in Poverty: The Case of Peru", Journal of Develonment Economics Vol.7, 85-98.

World Bank 1990. Indonesia: Povertv Assessment and Strategy Report, World Bank Report No. 8034-IND. Washington DC.

World Health Organization (WHO) 1985, Energv and Protein Requirements, WHO. Technical Report Series 724, Geneva. 
Table 1: Consumptions in a Neighborhood of FEI-Based Poverty Lines for Indonesia

\begin{tabular}{|c|c|c|c|}
\hline & Unit & Urban & Rural \\
\hline Rice. & kg & 9.626 & 8.078 \\
\hline Com & $\mathrm{kg}$ & 0.079 & 1.655 \\
\hline Cassava & kg & 0.520 & 1.722 \\
\hline Fresh Fish & kg & 0.677 & 0.459 \\
\hline Dried Fish & ons & 1.646 & 1.792 \\
\hline Meat & $\mathbf{k g}$ & 0.034 & 0.029 \\
\hline Chicken & kg & 0.078 & 0.025 \\
\hline Chicken Eggs & $\mathbf{k g}$ & 0.195 & 0.054 \\
\hline Spinach/Kangkung & $\mathbf{k g}$ & 0.756 & 0.697 \\
\hline Tomato & ons & 0.890 & 0314 \\
\hline Cassava Leaves & $\mathbf{k g}$ & 0.209 & 0.630 \\
\hline Eggplant & $\mathrm{kg}$ & 0.113 & 0.218 \\
\hline Vegerable Soup & bles & 0.350 & 0.075 \\
\hline Vegctable Mrx & bles & 0.525 & 0.133 \\
\hline Onion & ons & 1.199 & 1.001 \\
\hline Garlic & ons & 0.184 & 0.137 \\
\hline Red Pepper & ons & 0.752 & 0.389 \\
\hline Cayenne Pepper & ons & 0.625 & 0.944 \\
\hline Tahu & kg & 0.371 & 0.147 \\
\hline Tempe & $\mathrm{kg}$ & 0.461 & 0.209 \\
\hline Rambutan & $\mathrm{kg}$ & 0.343 & 0.132 \\
\hline Yellow Bananans & kg & 0.256 & 0.779 \\
\hline Other Bananas & $\mathbf{k g}$ & 0.353 & 0.668 \\
\hline Papaya & kg & 0.179 & 0.123 \\
\hline Oil & liter & 0.166 & 0.338 \\
\hline Coconur & butir & $0.8 \div 3$ & 1.271 \\
\hline White Sugar & ons & 5.157 & 3.665 \\
\hline Brown Sugar & ons & 0.974 & 0.866 \\
\hline Tea & ons & 0.397 & 0.399 \\
\hline Coffec & ons & 0.418 & 0.540 \\
\hline Salt & ons & 1.550 & 1.937 \\
\hline Tamarind & ons & 0.203 & 0.156 \\
\hline Fish Paste & ons & 0.339 & 0.284 \\
\hline Soya Sauce & $10 \mathrm{ml}$ & 1.786 & 0.542 \\
\hline $\begin{array}{l}\text { Food and drink } \\
\text { spending outside home }\end{array}$ & $\mathbf{R p}$ & 1160.55 & 302.52 \\
\hline
\end{tabular}

Nate: Consumptions per person per month for SUSENAS samples within plus or minus

Rp. 500 per person of the BPS poverty lines; authors claculations from 1990 SUSENAS data tapes. 
Table 2: Alternative Poverty Measures for Indonesia 1990

\begin{tabular}{|c|c|c|c|c|}
\hline \multirow[t]{2}{*}{ Poverty Measures } & & \multicolumn{2}{|c|}{$\begin{array}{c}\text { Cost-of-basic-neris } \\
\text { method }\end{array}$} & \multirow{2}{*}{$\begin{array}{l}\text { Food- } \\
\text { energy- } \\
\text { intake } \\
\text { method }\end{array}$} \\
\hline & & Food only & $\begin{array}{c}\text { Food }+ \\
\text { non-food }\end{array}$ & \\
\hline \multirow{3}{*}{$\begin{array}{l}\text { Head-count Index } \\
\text { (\%) }\end{array}$} & Indonesia & 7.93 & 19.63 & 15.08 \\
\hline & Urban & 2.80 & 10.67 & 16.75 \\
\hline & Rural & 10.20 & 23.58 & 14.33 \\
\hline \multirow{3}{*}{$\begin{array}{l}\text { Poverty Gap Index } \\
\text { (\%) }\end{array}$} & Indonesia & 0.97 & 3.46 & 2.42 \\
\hline & Urtan & 0.31 & 1.67 & 3.23 \\
\hline & Rural & 1.26 & 4.25 & 206 \\
\hline \multirow{3}{*}{$\begin{array}{l}\text { Foster-Greer- } \\
\text { Thorbecke } P_{2} \\
\text { Index }(x 100)\end{array}$} & Indonesia & 0.18 & 0.87 & 0.66 \\
\hline & Urban & 0.06 & 0.40 & 0.94 \\
\hline & Rural & 0.24 & 1.08 & 0.53 \\
\hline
\end{tabular}

Note: CBN-based estimates are the author's calculations from BPS price data and 1990 SUSENAS data tapes. The FEI-based estimates are from BPS (1992). 
Table 3: Regional Poverty Profile for Indonesia 1990 by Alternative Methods

\begin{tabular}{|c|c|c|c|c|c|c|}
\hline \multirow{2}{*}{ Provinee } & \multicolumn{2}{|c|}{ Urban+rumal } & \multicolumn{2}{|c|}{ Urban } & \multicolumn{2}{|c|}{ Rural } \\
\hline & $\begin{array}{l}\text { Cost of } \\
\text { basic- } \\
\text { needs } \\
\text { method }\end{array}$ & $\begin{array}{l}\text { Food- } \\
\text { energy } \\
\text { intalke } \\
\text { method }\end{array}$ & $\begin{array}{l}\text { Coss of } \\
\text { basic- } \\
\text { needs } \\
\text { method }\end{array}$ & $\begin{array}{l}\text { Food- } \\
\text { encrgy } \\
\text { intulse } \\
\text { method }\end{array}$ & $\begin{array}{l}\text { Cost of } \\
\text { basic- } \\
\text { needs } \\
\text { method }\end{array}$ & $\begin{array}{l}\text { Food- } \\
\text { emergy } \\
\text { intake } \\
\text { method }\end{array}$ \\
\hline Acesh & 11.49 & 15.9.1 & 6.74 & 13.74 & 12.35 & 16.32 \\
\hline Norti Sumara & 12.05 & 13.53 & 8.18 & 14.44 & 14.12 & 13.03 \\
\hline Wes. Sumntra & 13.35 & 15.01 & 0.92 & 11.15 & 16.38 & 15.99 \\
\hline Rinj & 13.07 & 13.66 & 4.89 & 8.75 & 16.86 & 15.96 \\
\hline Jambi & 11.23 & n.a. & 5.30 & n.as. & 12.81 & n-n. \\
\hline South Sumntra & 14.63 & 16.81 & 4.27 & 23.56 & 18.90 & 14.02 \\
\hline Bengkula & 24.56 & n.a. & 9.60 & n-a. & 28.16 & n.a. \\
\hline Lamping & 28.17 & 13.12 & 15.74 & 15.11 & 29.94 & 12.84 \\
\hline Jakarta & 1.30 & 7.79 & 1.30 & 7.79 & n.a. & - \\
\hline West Java & 17.61 & 13.89 & 16.21 & 20.87 & 18.32 & 10.21 \\
\hline Central Java & 24.69 & 17.49 & 11.13 & 22.00 & 29.54 & 15.83 \\
\hline Yogyakara & 17.22 & 15.50 & 10.68 & 19.18 & 22.10 & 1255 \\
\hline East Jave & 21.80 & 14.78 & 15.28 & 21.85 & 24.19 & 12.10 \\
\hline Bali & 12.19 & 11.21 & 9.68 & $16.60^{\circ}$ & 13.05 & 9.27 \\
\hline $\begin{array}{l}\text { Wert Num } \\
\text { Tenggara }\end{array}$ & 27.61 & 23.18 & 21.56 & 32.16 & 28.85 & 2130 \\
\hline $\begin{array}{l}\text { Enst Nusa } \\
\text { Tenggare }\end{array}$ & 45.62 & 24.06 & 17.95 & 18.02 & 49.06 & 24.84 \\
\hline West Kalimantan & 33.83 & 27.58 & 14.69 & 22.43 & 38.72 & 28.86 \\
\hline $\begin{array}{l}\text { Central } \\
\text { Kalimantan }\end{array}$ & 18.65 & nos. & 12.34 & n.a. & 19.94 & n.n. \\
\hline $\begin{array}{l}\text { South } \\
\text { Kalimantan }\end{array}$ & 8.69 & 21.17 & 0.87 & 19.16 & 11.54 & 21.91 \\
\hline East Kalimantan & 17.00 & a.s. & 4.85 & n.a. & 2354 & n.x- \\
\hline North Sulawesi & 18.79 & 14.88 & 5.16 & 11.01 & 22.71 & 16.02 \\
\hline Cextral Sulawesi & 24.91 & n.a. & 2.18 & n.a. & 29.20 & n.a. \\
\hline South Sulowesi & 23.12 & 10.79 & 15.22 & 17.32 & 25.58 & 8.71 \\
\hline $\begin{array}{l}\text { Southeast } \\
\text { Sulawesi }\end{array}$ & 28.84 & n.a. & 16.34 & ה.s. & 31.29 & na. \\
\hline Maluku & 29.04 & n.a. & 7.34 & n.a. & 33.93 & n.n. \\
\hline Irian Jayn & 12.61 & n.x. & 12.61 & n.a. & n.a. & n.s. \\
\hline Aggregate & 19.63 & 15.08 & 10.67 & 16.75 & 23.58 & 14.33 \\
\hline
\end{tabular}

Note: The table gives the percentuge of each subgroup"s population deemed to be poor by each method. The FEI-based estimates are from BPS (1992). The CBN-based estimales are the author's calculations from BPS price data and 1990 SUSENAS data tapes. 
Table 4: Poverty Profile by Sector of Employment Using Alternative Methods

\begin{tabular}{|c|c|c|c|c|c|}
\hline \multirow{2}{*}{$\begin{array}{l}\text { Principal } \\
\text { Sector of } \\
\text { Employment }\end{array}$} & \multirow{2}{*}{$\begin{array}{l}\text { Laborer' } \\
\text { Self } \\
\text { Employed }\end{array}$} & \multicolumn{2}{|c|}{ Urban } & \multicolumn{2}{|c|}{ Rural } \\
\hline & & $\begin{array}{c}\text { Cost-of- } \\
\text { Basic-Needs } \\
\text { Method }\end{array}$ & $\begin{array}{l}\text { Food } \\
\text { Energy } \\
\text { Method }\end{array}$ & $\begin{array}{l}\text { Cost-of- } \\
\text { Basic-Needs } \\
\text { Method }\end{array}$ & $\begin{array}{l}\text { Food } \\
\text { Energy } \\
\text { Method }\end{array}$ \\
\hline \multirow[t]{2}{*}{ Farming. } & L & 21.53 & 35.23 & 32.37 & 19.24 \\
\hline & SE & 20.33 & 33.33 & 26.29 & 15.79 \\
\hline \multirow[t]{2}{*}{ Mining } & $\mathbf{L}$ & 8.68 & 16.86 & 9.79 & 4.95 \\
\hline & SE & n.a. & n.a. & 25.35 & 8.86 \\
\hline \multirow[t]{2}{*}{ Industry } & $\mathbf{L}$ & 10.24 & 20.29 & 14.97 & 5.82 \\
\hline & SE & 13.78 & 25.78 & .25 .33 & 14.08 \\
\hline \multirow[t]{2}{*}{ Consiruction } & L & 15.02 & 31.06 & 17.21 & 8.70 \\
\hline & SE & 12.05 & 20.50 & 13.95 & 7.60 \\
\hline \multirow[t]{2}{*}{ Trade } & $\mathbf{L}$ & 6.93 & 13.09 & 16.66 & 8.04 \\
\hline & SE & 9.50 & 19.26 & 14.76 & 7.00 \\
\hline Transport & L & 6.25 & 14.63 & 12.02 & 6.23 \\
\hline . & SE & 19.03 & 32.19 & 14.02 & 6.22 \\
\hline Finance & L & 1.19 & 3.02 & 7.58 & 8.91 \\
\hline Service & L & 3.95 & 9.89 & 6.59 & 3.65 \\
\hline & SE & 12.96 & 20.53 & 16.82 & 7.86 \\
\hline Other & $\mathbf{L}$ & 9.00 & 19.54 & 20.90 & 13.92 \\
\hline Transfers & L & 4.74 & 10.23 & 11.99 & 6.49 \\
\hline
\end{tabular}

Note: Sectors with small sample sizes (population less than 0.1 ) have been omitted from the analysis. These are selfemployed urban mining, self-employed finance (both urban and rural). self-employed others (both uroan and rural) and the entire sector of electrieity, water and gas.

- Sector Definitions

Farming: farming. husbandry, forestry, hunting and fishing

Mining: mining and excavating

Industry: industrial processing

Trade: wholesale, retail. restaurant and hotel .

Transpor: transporation, warehousing and communication

Finance: finance, insurance, building rental, real estate and office services

Service: community services. socinl servies and personal services

Transfers: pension, relatives, gifis ete. 